\title{
Research in non-university higher education institutions. The case of the Swiss Universities of Applied Sciences
}

\author{
Benedetto Lepori
}

Published online: 4 August 2007

(C) Springer Science+Business Media B.V. 2007

\begin{abstract}
This paper presents the development of research in the Swiss non-university higher education sector and frames it in the debate on the organization of higher education systems in Western Europe and on the dynamics between university and non-university sector. It shows that, in the Swiss case, the applied research mandate has been used to differentiate these institutions from universities and that this endeavor has been to a large extent successful in technology, while it has been a source of major tensions in the other domains. I conclude that the development of research in the non-higher education leads to complex dynamics of convergence and of differentiation and that this process is strongly influenced by the specificities and differences between different subject domains.
\end{abstract}

Keywords Non-university higher education - Binary divide - Applied research · Switzerland

\section{Introduction}

A well-known evolution in most European countries in the last decades has been the creation of a "second" higher education sector, composed by institutions oriented towards professional education (Huisman and Kaiser 2001); with a few exceptions (Italy, Spain, the UK), this model characterizes nowadays most Western European countries (Kyvik 2004). The creation of these institutes was mainly motivated by educational concerns, to improve the quality of professional tertiary education through institutional restructuring on one side, and to absorb a part of the increase in higher education enrolments on the other side.

However, the policy aim of creating education-only institutions largely failed (OECD 1998), since in most countries non-university higher education institutions have been granted the right of developing research activities. While in the earlier cases this was

B. Lepori $(\bowtie)$

University of Lugano, via Lambertenghi 10a, Lugano 6904, Switzerland

e-mail: blepori@unisi.ch 
pushed by the institutions themselves, in recent cases like in Finland (OECD 2003b), Switzerland (Lepori and Attar 2006) and Norway (Kyvik and Skovdin 2003) a specific research mandate has been actively promoted by the State.

The aim of this paper is to understand through the analysis of the Swiss case the implications of the research mandate for the dynamics of a binary system. Namely, I will argue that the development of research in non-university institutions cannot be subsumed under the notion of academic drift only (Burgess 1972), but entails a dynamics of specialization and differentiation concerning research. Thus, depending on how it is implemented, the research mandate can lead to a convergence between the two sectors, but also to a stronger differentiation and to the reinforcement of the binary divide.

In this context, the Swiss case is interesting since Swiss Universities of Applied Sciences (UAS) not only received a research mandate from their creation, but there has been also an active policy of the Swiss government to develop research, including the provision of dedicated funds and support measures. This policy can be interpreted as an attempt to promote the specialization of the higher education system between international universities and regional providers (Larédo 2003) through regulatory measures and incentives, in a system where competition between individual institutions is limited by the federal organization of the country (Perellon 2001; Lepori 2007). Thus, looking at this experience promises some lessons concerning the development of research and the future of the binary system, in face also of the pressures towards an increasing specialization and differentiation in the university sector (Bonaccorsi and Daraio 2007).

The paper is organized as follows. In the first section, I outline the development of the Swiss universities of applied sciences and frame it in the context of the evolution of higher education systems in Western European countries. In the second section, I focus on the research mission and on the development of research during the last ten years. In section three, I discuss some central issues for the positioning of UAS in the Swiss research system. Finally, I draw general conclusions and lessons for higher education studies.

\section{Differentiation and the creation of a binary system}

Differentiation is one of the most debated issues in higher education studies (Meek et al. 1996; Teichler 2003). It is widely acknowledged that the expansion of higher education in advanced countries since the " 60 led to increased diversity, as a consequence of diversification of functions and of the increasing specialization at the disciplinary level, but also as a means to preserve elite higher education and research in face of massification (Trow 1974; Teichler 2002 and 2003). More or less explicitly, it was also assumed that in today's mass system some level of institutional diversity is desirable since it allows higher education to better respond to social needs and thus it should be actively promoted by the State (Goedegebuure et al. 1996).

A fundamental distinction in this respect is between systems promoting diversity through competition between individual institutions-where all of them are in principle granted the same status-and systems where the State defines different categories of institutions, with different missions, status and rules, with an university sector alongside a non-university sector composed by institutions oriented towards professional education, with no or a limited research mandate and not having the right of granting PhDs (binary systems, Huisman and Kaiser 2001; Kyvik 2004). This distinction can be interpreted as the result of two policies to achieve differentiation (Bleikie 2003). Thus in unitary systems, differentiation is pursued through competitive mechanisms in the allocation of resources, 
which select a restricted number of high-level research institutions (for example in the US "stratified" system; Kyvik 2004) alongside a larger number of less intensive research universities and of essentially teaching-only institutions, while in binary systems the State attributes ab initio a distinct mandate to the non-university sector, focused on vocational education and with a restricted (or no) research mission; independently of their performance, institutions are not allowed to switch from a sector to the other, except by State decision. Thus, binary systems can also be seen as a way of avoiding a hierarchical classification of institutions by putting them in different classes.

Binary systems began to emerge in the ' 60 and the '70-UK Polytechnics were created in 1965 and German Fachhochschulen in 1971-as an explicit policy answer to the increasing demand for higher education: it was believed that the creation of new vocational higher education institutions was likely to answer best the need for professional qualifications and would allow to preserve universities from increasing enrolments (Kyvik 2004). Since then, the non-university sector has been subject to a complex pattern of change over the last decades (Kyvik 2006), while the binary divide itself has proved to be unstable and interactions between university and non university sector have taken place (Huisman and Kaiser 2001; Kyvik 2006). This is the case for educational offers-where the distinction between academic and vocational curricula has become blurred-and for research, where most non-university institutions developed research and strived to achieve the same status as universities. At a system level, the UK has come back to a unitary system in 1992, while convergence has progressed to a large extent in Norway where Colleges can ask to change to an university status; at the contrary, some of the newly created systems like Finland or Switzerland are characterized by a clearer divide between the two sectors.

\section{A quite typical case...}

In this context, Switzerland followed a typical path. Namely, the seven universities of applied sciences have been created in 1997 by grouping and reorganization of more than sixty tertiary-level professional institutions in the fields of technology, economics and management, and applied arts (Lepori and Attar 2006; Perellon 2003). The rationale was to upgrade tertiary vocational education by creating larger institutions with a higher education status; a further motivation was to provide technology support to Small and Medium Enterprises (SMEs) in the regional context. The reorganization was based on geographical criteria: each UAS covers a part of the Swiss territory, but most of them happen to cover different Cantons.

UAS joined the ten cantonal universities, most of them being generalist universities covering most of the subject domains, and the Federal Institutes of Technology in Zurich and in Lausanne, which have the same degree structure of universities, but are concentrated on natural sciences and technology and are under the direct sovereignty of the central state (Lepori 2007).

In the last ten years, UAS have strongly expanded by integrating tertiary vocational schools in domains like social work, health, arts, teacher education. As a consequence, student's numbers have grown from about 24,000 students in 2000 to 50,000 in 2005 and UAS have evolved also from institutions focused on engineering and technology (which made about half of the students in 1998) to generalist institutions covering most of the fields and with $3 / 4$ of students in non technical domains. According to today's forecasts, the number of bachelor diplomas awarded by UAS will exceed in the next years those awarded by universities (Bundesamt für Statistik 2006). 
The creation of UAS has been decisive to promote the expansion of higher education in a country historically characterized by a very low participation rate to higher education (International Standard Classification of Educational Degrees ISCED 5A level) and by a very large tertiary professional sector (ISCED 5B level; OECD 2003a). The entry rate to ISCED 5A increased from $16.1 \%$ in 1995 to $32.1 \%$ in 2004 (source: Swiss Federal Statistical Office). This led also to a strong increase of educational expenditures since upgrading vocational education entailed also an increase of the costs per student. Public expenditures in tertiary education were stable around 1\% of GDP from 1981 to 1995/6 and then increased to $1.6 \%$ in 2005 (source: OECD. Education at glance).

Finally, UAS are characterized by a complex governance structure being subject to federal (framework) regulations while the institutions themselves are subject to cantonal rules, being the result of the transformation of former cantonal professional schools. As a consequence, the responsibility for the steering of the system is fragmented among different bodies and jurisdictions (Lepori 2007; Perellon 2003). Moreover, five out of the seven UAS are based on an intercantonal agreement, whose modifications have to be agreed by all partners and where each partner Canton tends to deal directly with the schools located in its region, weakening the overall management.

As a consequence, both the UAS peer review (Commission fédérale des HES 2002) and our work has showed a great deal of variation in the strength of the central UAS directions and in the progress of their transformation from groupings of individual schools to more unitary structures. Key elements of this process are the creation of a governing board and the nomination of a director with strong power; the centralization of the allocation of financial resources; the reorganization in subject departments and the concentration of subject domains in a single location. These differences and the complexity of the governance structure have a deep impact on the ability of UAS to develop their research profile.

\section{The emergence of a new research actor}

Starting from a low level, Swiss UAS have grown in the last ten years to significant actors in the Swiss research landscape. Information presented is based on material collected for an assessment of UAS research strategies commissioned by the Swiss Innovation Agency. This included the consultation of documents on research strategies and activities and 22 face-to-face interviews to people with institutional responsibilities ( 9 of them were directors of a UAS or of a department while 13 had a specific responsibility concerning research at the level of the UAS or of a department, like "pro-rectors research"). Table 1 shows that coverage was quite complete for technological departments, more limited for economics and social work and limited for the other domains. These differences in

Table 1 Interviewed persons by UAS and domain

\begin{tabular}{llllllllr}
\hline & BFH & FHNW & FHO & FHZ & HESSO & SUPSI & ZFH & Total \\
\hline Technology and construction & 2 & 2 & 2 & 1 & 2 & 1 & 2 & 12 \\
Economics & 1 & 0 & 1 & 1 & 0 & 1 & 0 & 4 \\
Social work and health & 0 & 0 & 0 & 0 & 2 & 1 & 1 & 4 \\
Arts & 0 & 0 & 0 & 0 & 0 & 0 & 1 & 1 \\
UAS direction & 0 & 1 & 0 & 0 & 0 & 0 & 0 & 1 \\
Total & 3 & 3 & 3 & 2 & 4 & 3 & 4 & 22 \\
\hline
\end{tabular}


coverage have to be considered in interpreting the results, even if these domains represent the bulk of today's research activity.

This information has been completed through an on-line questionnaire to UAS researchers, which was explicitly targeted to people having a managing role in research, like heads of laboratories or of institutes, selected from organizational charts and the web sites. The total number of answers was 140, rather evenly distributed among the seven UAS and between subject domains in relationship to their research volume (see Lepori and Attar 2006). This is a rather high number considering that overall UAS have about 1000 FTE in research. Fifty-five percent of the respondents characterize their function as research managers and a further $18 \%$ as senior researcher.

\section{Research in the non-university higher education sector: an overview}

Even if it was not foreseen from the beginning, in almost all European countries nonuniversity institutions got the right of performing research (OECD 1998) and initiatives have been undertaken to develop it (like the institution of the lectorates in the Dutch Hogescholen; Boezerooy 2003). This trend has been explained by the strive of these institutions to raise their status and thus become more similar to universities ("academic drift"; Burgess 1972), as well as the desire of the staff to improve its status and working conditions by doing research (Kyvik 2006). A study on the Norwegian colleges (Kyvik and Skovdin 2003) shows that they are faced with a number of issues originated by their vocational orientation and by the lower research intensity, as well as by the differences between domains and individuals concerning research competences. Hence, the definition of priorities and the allocation of resources for research between domains and staff are more complex than in universities.

At the political level, the discussion on research in the non-university sector has led to two main types of responses. The first one, as in the UK and in Australia, has been to grant to these institutions the same status as universities, including the right of awarding PhDs. There have been a number of criticisms arguing that this policy led to the creation of a twoclass system with strong differences between institutions (Parry 2003).

An alternative has been to define a mandate focused on applied research and services to the local economy. It has been argued that this type of research is more compatible with the professional orientation of these institutions (Pratt 1997). In other words, the research mandate has been used as an element of the differentiation between the two sectors. The Swiss case is typical for this approach, which is present also in other countries like Finland (OECD 2003b) or Germany with its program to promote collaborative projects between Fachhochschulen and private companies (BMBF 2004).

The issue is linked to the debate on the future of European higher education. Namely, empirical evidence shows that European systems are characterized by a limited differentiation (Bonaccorsi and Daraio 2007); the implication which is often drawn is that public policies should focus stronger on excellence and target financial support to the best universities. However, others have remarked that in the European context most universities fulfill also a function of proximity knowledge provider, addressing the needs of SMEs and of local communities and thus that differentiation of research profiles-rather than concentration —would be a more adequate strategy (Larédo 2003). The attribution of a specific research mandate to the non-university sector can be interpreted as an attempt to solve this tension between world-class research and proximity research using the binary divide as a way of specializing institutions. 


\section{The research mandate and its promotion}

The UAS Act of 1995 provides the UAS a distinction with universities in the research mandate, since it states that research in UAS should be applied and oriented to the needs of the regional economy (Conseil fédéral 1997). Thus, UAS are considered to be downstream of the production of basic knowledge by universities towards its application (OFFT 2002).

This choice has to be seen also in the context of a research system where universities are the dominant actor to an extent unknown in other European countries-with public research organizations reduced to a largely marginal role - and where it is considered that research is an essential and necessary component of the mandate of all universities (Lepori 2006). Thus, all international comparisons display a very good position of Swiss universities, with the two Federal Institutes of Technology ranking among the best European universities in bibliometric analyses (CEST 2003); more in-depth studies show however that this favorable situation, concerning research resources and intensity, number of $\mathrm{PhD}$ students, and scientific publications holds true in natural sciences, medicine and biology, while research is weaker in social sciences and humanities, where about $2 / 3$ of the university students concentrate (Lepori 2007).

Since the former schools had very limited research experience, the Confederation developed an active promotion policy; in 1997 additional means were provided to the Swiss Innovation Agency (CTI) to coach UAS in the development of research (Conseil fédéral 1997; Mayer et al. 2006); moreover, national competence networks were financed to promote cooperation between UAS in specific fields. At the same time, the Swiss Innovation Agency received a strong budget increase and was largely reoriented to support UAS. Finally, to promote the development of practice-oriented research in domains like social work, health, music and arts, the DO-RE ("Do Research") program was launched jointly by the Swiss Innovation Agency and the Swiss National Science Foundation (SNF). Thus normative pressure was backed up with concrete financial support.

In fact, the creation of UAS was the result of the conjunction of two policy streams. The first one was the upgrading of professional education, which started at the beginning of the '90s with the creation of a professional diploma at the secondary level (Perellon 2003; OECD 2003a). The second was the development of a policy for technological development and innovation in SMEs, after the experiences of the '70s and the ' 80 s had showed that the traditional liberal approach of the Swiss research policy had failed to achieve this goal (Lepori 2003). The strengthening of the Swiss Innovation Agency and the creation of an actor devoted to applied research and transfer were the main initiatives in this direction, following also strong criticisms from the OECD (OECD 1989).

However, in the recent years, some conflicts have emerged between these two objectives. Namely, while the Confederation promoted the development of research, the Cantons pushed to integrate in UAS most of the vocational education, thus setting the priority in the upgrading of professional tertiary education.

\section{A success story}

In the last ten years research in UAS has developed strongly. Total R\&D expenditures have increased from 80 mio. Sfr. in 2000 to 194 mio. in 2005 and the overall estimation is that the volume of research has increased at least five-fold in ten years. UAS also have been successful in getting funds from the CTI for collaborative projects with private companies, as well as direct contracts from the companies themselves (26 mio. in 2004 from the CTI 
and 34 mio. Sfr. from private contracts). Moreover, in a recent survey the number of companies mentioning UAS as a partner in technology transfer was very close to those mentioning the two Federal Institutes of Technology and much higher than regarding cantonal universities (Arvanitis et al. 2005). Research is also now clearly identifiable in the website of all UAS and of most departments and in most cases indications are given about research domains and units (institutes, laboratories).

A further sign of consolidation is the development of a layer of scientific collaborators devoting about half of their time to research, which now account for about $2 / 3$ of the R\&D effort, while teaching is largely performed by part-time professionals. Thus UAS have moved away from the model of the teacher doing some research towards the recruitment of specialized staff.

At the same time, five out of the seven UAS have produced a strategic document concerning research. Earlier documents of the period 2000-2003 have been mostly concerned with the establishment of general principles, the set-up of structures and internal funding mechanisms, while recently at least four of the seven UAS have developed a list of competence or priority domains. At the management level, five out of seven UAS created a research commission, in charge of developing strategies and of managing central research funds; the exceptions are the two UAS where overall central structures do not exist. Four out of seven UAS dispose of internal project funds allocated by competitive procedures. Additional funding through external contracts is also a widespread practice.

If compared to the starting situation these developments are impressive, but in quantitative terms UAS account for only about $7 \%$ of the total R\&D expenditures of the Swiss higher education sector. On the average, UAS spend only about $14 \%$ of their budget for $\mathrm{R} \& \mathrm{D}$ against more than $50 \%$ in universities.

Most respondents consider that their team is either a regional service provider or one of the actors at national level, but just one fifth of them rates them as the best in the country and with international visibility (Table 2). Also, most respondents signaled that their team was too small to compete with other players and to ensure a regular flow of funds. In fact, the main issue is not shortage of funds, but dependence on a small number of contracts, meaning incertitude and difficulty in developing human resources. Most of them agreed that further consolidation and focalization on priority domains is necessary.

Table 2 Size and position of research teams

\begin{tabular}{lr}
\hline How would you position your team in the Swiss research landscape & $\%$ \\
\hline We are the best in Switzerland in our domain and we are internationally recognized & $22 \%$ \\
We are recognized nationally even if there are stronger teams in the same domain & $49 \%$ \\
We are a regional research/service provider & $34 \%$ \\
We are rather marginal & $11 \%$ \\
\hline
\end{tabular}

How do you evaluate the size of your team?

Sufficiently large

Note: The table gives the $\%$ of the total number of respondents $(N=140)$ who choose each option; multiple choices were possible 


\section{Differences between subject domains}

This aggregated view oversees the extreme differences between sectors. Namely, the development of research has taken place essentially in technology (including construction and chemistry), which accounted in 2004 for $70 \%$ of the research volume. In these domains the share of research in the overall activities exceeds $20 \%$; while significantly lower than universities (where the share of $\mathrm{R} \& \mathrm{D}$ reaches $50 \%$ ), it means that research is a major activity at the department level (see Table 3). In domains with an R\&D share lower than $10 \%$ research can be a relevant activity of some subunits, but these are in largely teachingonly departments. Moreover, since these data cover the seven UAS and, in some of them subject domains are not concentrated in a single location, the volume of research in all domains outside technology is insufficient to maintain sizeable research units everywhere.

Our interviews confirmed this view. Most technology departments of UAS are recognized regional centers of applied R\&D and transfer, with a considerable portfolio of projects and of competences. Unsurprisingly, all of them are in medium-size towns outside the cities hosting the two federal institutes of technology and the large cantonal universities. These departments made the largest progress in the consolidation of research in institutes, in developing management capacities and specialized personnel, including fulltime researchers but also young researchers who provide most of the workforce and, after 3-4 years of experience, leave to the private industry.

In other domains, like economy, social work and design, we identified a number of research units of smaller size (typically five to ten people), scattered in basically teaching departments. Competences are a major problem, since practical experience (for example in the private economy) is no substitute for methodological competences requiring a

Table 3 Research resources and research intensity in UAS per domain

\begin{tabular}{|c|c|c|c|c|c|}
\hline & \multicolumn{3}{|c|}{ Personnel } & \multirow{2}{*}{$\begin{array}{l}\text { Students } \\
2005\end{array}$} & \multirow{2}{*}{$\begin{array}{l}\text { Intensity } \\
\text { (1) }\end{array}$} \\
\hline & FTE & FTE R\&D & $\% \mathrm{R} \& \mathrm{D}$ & & \\
\hline Architecture and construction & 532 & 116 & 22 & 2,867 & 4.0 \\
\hline Technology and informatics & 2,001 & 608 & 30 & 10,088 & 6.0 \\
\hline Chemistry and life sciences & 330 & 68 & 21 & 1,321 & 5.1 \\
\hline Agriculture and forestry & 107 & 26 & 24 & 369 & 7.0 \\
\hline Economy & 1,333 & 136 & 10 & 15,300 & 0.9 \\
\hline Design & 389 & 40 & 10 & 2,309 & 1.7 \\
\hline Sport & 15 & 5 & 33 & 86 & 5.8 \\
\hline Music and Theater & 757 & 24 & 3 & 4,298 & 0.6 \\
\hline Linguistics & 43 & 1 & 2 & 266 & 0.4 \\
\hline Social work & 605 & 75 & 12 & 4,624 & 1.6 \\
\hline Psychology & 79 & 6 & 8 & 513 & 1.2 \\
\hline Health & 442 & 23 & 5 & 1,626 & 1.4 \\
\hline Teacher training & 1,841 & 100 & 5 & 10,358 & 1.0 \\
\hline Undivided & 1,249 & 35 & 3 & 115 & - \\
\hline Total & 9,724 & 1,264 & 13 & 54,140 & 2.3 \\
\hline
\end{tabular}

2005, data from the Swiss Federal Statistical Office

FTE: full time equivalents

(1) Human resources in R\&D activities (FTE) per 100 students 
university degree and since most of the teachers have no research experience. Finally, in some of the newly integrated domains, like music, theater, health and, to some extent, teacher training, there is practically no research tradition in Switzerland.

\section{Finding their place in the research systems}

Even if the pessimistic evaluation of the recent OECD report on the Swiss innovation system seems to be exaggerated (OECD 2006), it remains that UAS are faced to a number of structural issues in their development of research (Lepori and Attar 2006). I will focus here on three of them: the interpretation of the applied mandate, competition with education for funding and, finally, organizational and structural issues.

\section{Positioning: the myth of the divide between basic and applied research}

In discussing the applied research mandate, we need to distinguish between the normative level and its practical application and to discuss their interactions.

At the normative level, the applied research mandate is considered by all actors as the key element in defining the position of UAS in the Swiss research landscape and there are no discussions about a weakening of the distinction with universities. The most recent document of the UAS rector's conference adds some flexibility, since some development of basic knowledge is foreseen where needed for practical application, while it is excluded that UAS engage in basic research for itself (KFH 2005).

In political terms, the discourse about the need of an actor more oriented towards private companies has been crucial in promoting the development of research in these institutions and in justifying its funding (Conseil fédéral 1997). This was backed up by a general discourse about the inability of the Swiss system to transfer research results towards the economy and about the lack of a technological policy (OECD 1989; Conseil fédéral 1992).

In practical terms, the experience shows that in technology the focus on application and the orientation towards the needs of SMEs allowed UAS to build a specific profile, even with different interpretations; thus our interviews show that some departments are more directly driven by demand from private industry (with a broader portfolio of competence focused on development), while others are more concentrated on specific application domains and thus are moving to some extent towards more long-term research. This orientation has also been implemented in the policy concerning research personnel, which is required to have an experience in private companies.

Two factors made this profiling easier. Firstly, in the Swiss context technical sciences are concentrated in the Federal Institutes of Technology. They cooperate with private companies, but profile themselves as leading international research universities and thus institutional competition with UAS is limited. Secondly, there is a separation of funding between basic research (through the Swiss National Science Foundation) and industryoriented research (through the Swiss Innovation Agency) and, in practice, UAS have access only to the second channel.

Outside technology, research managers are not very comfortable with the applied research mandate or, even, deny that it is a useful guidance. This is the result of different factors: the lack of a workable distinction between basic and applied research and of accepted concepts of what is applied research for example in social sciences or in economy; a stronger competition with cantonal universities, which are more present in the 
regions and in some fields perform essentially applied research; the weakness of the funding instruments for applied and practice oriented research and the lack of clearly identifiable customer like companies (the amount of public administration mandates being much smaller). A final factor is that, unlike in technology, in most of these domains there is no distinct competence profile for a UAS researcher, since methodological competences required are largely the same as in university and practical experience plays a more limited role. Thus, UAS units outside technology recruit most of their personnel directly from graduates and $\mathrm{PhDs}$ of universities. A sign of these differences is the fact that in these fields scientific publications are ranked much higher than in technology, where applied outputs like services to companies are considered the most important research output (see Table 4).

This discussion shows that it is difficult to identify a specific niche for UAS research in these sectors which is compatible with their applied and service mandate as defined from technology. What emerges is that for a generalist institution it is more complex to focus on a specific type of research than for a specialized one, since these distinctions and their practical implementation are largely domain-specific. Thus, Swiss UAS are confronted with a difficult choice: broadening the research mandate would help to find suitable approaches outside technology, but at the price of weakening their identity and risking to loose political support. Taking the opposite way entails the risk of reinforcing the divide between technological departments, active both in professional education and in applied research, and teaching-only departments in other domains.

\section{Education and research: competition for funding}

A related issue is competition of funding between education and research and the fact that education is the stated political priority for UAS. Thus, the plan of the Swiss government states that the long-term objective is to devote $20 \%$ of the budget to R\&D from today's level of 14\%, while medium-term objectives are even more modest (Conseil fédéral 2007).

What makes this competition relevant is the increase of the student's numbers and the high costs per student in social sciences. Namely, even if data should be treated with care since accounting systems are different, in technical sciences educational costs per student in UAS are similar to universities, while in social and human sciences they are significantly higher.

This is not surprising since UAS have maintained the model of small classes in most of their activity domains, with small ratios of students to teachers, while universities have a

Table 4 Main research outputs: number of answers

\begin{tabular}{llr}
\hline Main output indicated & No. of responses & Other \\
\cline { 2 - 3 } & Technology & 42 \\
\hline Scientific publications & 10 & 2 \\
Patents or technological results & 20 & 23 \\
Services to industry & 55 & 23 \\
Services to public administration & 15 & \\
\hline
\end{tabular}

Note: The table gives the number of respondents $(N=140)$ indicating an item in the list as the main output of research (other possibilities: important, non important). Respondents are divided between fields of activity as indicated in the questionnaire. Technology includes technology, architecture and construction, chemistry and life sciences 
strongly differentiated model, with high students to teacher ratios in social sciences and much smaller ratios in natural sciences, technology and medicine; costs per student differ accordingly (Filippini and Lepori 2007). Since in the last two decades the increase in student's numbers was concentrated in social sciences, educational costs did not rise to the same extent as enrolments.

Since UAS profile themselves as providers of quality professional education this does not easily allow a reduction of the costs per student to compensate the increasing numbers. Moreover, while in technology the level of research activities makes integration with education feasible (for example in diploma work) and thus benefits of the joint mandate are apparent, in other domains the development of research is a cost subtracted to education (at least in the short run).

This issue was overseen at the beginning because of the assumption that UAS research, being market-oriented, could be funded by external sources. However, in $2004 \mathrm{R} \& \mathrm{D}$ expenditures were covered only by $40 \%$ with external sources and thus even in technology the development of research has been possible only thanks to a substantial investment from the general budget and this will be even more the case in soft sciences.

Thus UAS are caught in a dilemma: developing research outside technology will be possible only by subtracting resources to education, in a context where educational costs are already under pressure. Not only this is not acceptable politically, but it would also impair the main marketing argument in education, namely specific professional education in small classes. However, today's level of research outside technology is too low to justify its existence in a long-term perspective and would lead to pressures to limit the research mandate to technology (as already advocated by Economiesuisse).

\section{Institutional complexities and limits to governance}

This analysis displays the complexity of developing at the same time research and education in the non-university higher education sector. Namely, some of the features which are source of tensions have been at the same time, in the Swiss context, key ingredients of the success of UAS: thus the research mandate and the related higher education status was crucial to raise their status and to justify the increase of public support. The applied research mandate allowed UAS to distinguish them from universities and to justify the development of a type of research which was supposedly not sufficiently developed. And finally the merging process has been crucial to build institutions with visibility at the national level even if it makes more difficult the definition of a unitary profile.

However, these features originate tensions at the system level and inside the individual institutions, which might lead, in the future, to reconfigurations. My interviews showed that this perception of an unstable situation is largely accepted by the involved actors. Moreover, the new higher education act which should come into force in 2012 will introduce new rules and a reform of the financing mechanisms of the whole system (Département federal de l'intérieur 2004) and these reforms are likely to have a significant impact on UAS.

In this context, the least likely scenario seems to be removing the binary divide and attributing to UAS a general research mandate, possibly with the right of awarding PhDs. Not only the binary divide is largely accepted as a basis for the organization of Swiss higher education, but it has also been implemented in different rules for the management of the two sectors (including different funding mechanisms) and in the separation of the governance structure (universities and UAS are under the responsibility of two different 
ministries). In the Swiss context, with its strong institutional stability, these barriers will be difficult to overcome.

However, there are also reasons linked to today's development of UAS. Namely, in technology, where UAS are a significant research actor, they have developed a distinctive profile based on the applied research mandate, while there are no strong forces pushing towards convergence with universities. In the other domains UAS are essentially educational institutions and thus, getting a university status is not a priority at the institutional level (even if some researchers might push in this direction).

A more likely scenario would be that UAS cannot stand internal tensions and the two models are singled out, thus separating technological schools, with a research mandate, from generalist teaching-only professional schools. A stronger variant would be to go towards more specialized schools, with UAS in the domain of arts, economics, social sciences. The strong increase of student's numbers in the last years means that also specialized UAS would have sufficiently large numbers of students to be significant actors in higher education.

A further scenario would be that UAS are able to develop a sufficiently unitary profile across all domains, as well as sizeable research activities outside technology (at least in some domains). Considering today's context and available resources, this requires some more active institutional policies. Examples are the reduction of educational costs to free resources, the definition of priority domains where to concentrate efforts, selective human resources policies hiring people with research experience. In the medium and long-term this scenario would probably lead to a broadening of the research mandate and to some convergence with universities. However, it requires a reinforcement of the capability of UAS directions to define priorities and to implement policies for developing research. Given their organization and governance, it seems likely that only some of the seven UAS will be able to pursue this direction, while for the more decentralized UAS this scenario would probably require breaking them into smaller and more coherent geographical units.

\section{Conclusions}

To conclude, I would like to draw some lessons concerning the development of the higher education system and of the binary divide.

Firstly, the Swiss experience shows that the introduction of an explicit research mandate adds a level of complexity in the development of non-university higher education, internally to the institutions themselves, as well as in the whole system. This dynamics cannot be subsumed with the notion of academic drift because defining a specific research mandate for these institutions promotes their differentiation by creating an alternative norm to the "university" model. However, the outcome of this process depends largely on the extent to which this norm can be enacted by finding a specific niche for research in UAS compatible with this mandate.

Secondly, this process has a strong sectoral dimension due to conceptual aspects- the distinction between basic and applied research being largely sector-dependent-and to organizational aspects-different starting levels in research between sectors and different environmental conditions in terms of competitors and niches for research. Also, the relationship between research and vocational education, which is the core of the UAS mandate and of their success, is rather different according to the domain. These differences are a major source of internal tensions and make the definition of a unitary profile difficult (in a 
context where this is already a major issue because of the origin of UAS as conglomerates of regional schools).

Thirdly, the analysis of the non-university higher sector requires carefully considering not only the institutions as a whole, but also their subject domains, exactly because issues of convergence and differentiation and, more in general, of interactions with the university sector take quite different shapes according to the domain. As the Swiss example displays, this interaction between institutional-level mission and governance-related to the institutionally-defined binary divide — and the specific context of each domain, where the real-life of education and research takes place, is a key to understand the evolution of the non-university sector.

Aknowledgments The author wishes to thank the Swiss Innovation Promotion Agency which financed this study, as well as the persons interviewed and those who answered to the on-line questionnaire. Moreover, he thanks Mrs. Liliana Attar for support in the study.

\section{References}

Arvanitis, S., Kubli, U., Sydow, N., \& Wörter, M. (2005). Knowledge and Technology Transfer (KTT) activities between universities and firms in Switzerland: The main facts. Zurich: KOF-ETHZ.

Bleikie, I. (2003). Hierarchy and specialisation: on the institutional integration of higher education systems. European Journal of Education, 38(4), 341-355.

BMBF. (2004). Forschungslandkarte Fachhochschulen. Bonn: Potenzialstudie.

Boezerooy, P. (2003). Higher education in the Netherlands. Country report. Twente: CHEPS

Bonaccorsi, A., \& Daraio C. (Eds.) (2007). Universities as strategic units. Productivity and efficiency patterns in the European University system. Cheltenham: Edward Elgar.

Bundesamt für Statistik. (2006). Studierende und Hochschulabsolventen: Szenarien 2006-2015. Neuchâtel.

Burgess, T. (1972). The shape of higher education. London: Cornmarket Press.

CEST. (2003). Place scientifique Suisse 2001. Développement de la recherché en comparaison international sur la base d'indicateurs bibliométriques 1981-2001. Berne.

Commission fédérale des HES. (2002). HES 2002. Rapport sur la création des Hautes écoles spécialisées suisses. Berne.

Conseil federal. (1992). Technologiepolitik des Bundes. Bern.

Conseil fédéral. (1997). Message sur le financement de mesures de la Commission pour la technologie et l'innovation visant à créer, dans les hautes écoles spécialisées, les compétences nécessaires en matière de recherche appliquée et de développement durant les années 1998 et 1999 du 6 octobre 1997. Berne.

Conseil fédéral. (2007). Message sur le financement de la formation, de la recherche et de l'innovation 2008-2011. Berne.

Département fédéral de l'intérieur. (2004). Rapport sur la refondation du paysage suisse des hautes écoles. Berne.

Filippini, M., \& Lepori, B. (2007). Cost structure, economies of capacity utilization and scope in Swiss higher education institutions. In A. Bonaccorsi \& C. Daraio (Eds.), Universities as strategic units. Productivity and efficiency patterns in the European University system. Cheltenham: Edward Elgar.

Goedegebuure, L., Meek, V. L., Kivinen, O., \& Rinne, R. (1996). On diversity, differentiation and convergence. In V. L. Meek, et al. (Eds.), The mockers and the mocked: Comparative perspectives on differentiation, convergence and diversity in higher education. (pp. 2-25). Guilford, Pergamon.

Huisman, J., \& Kaiser, F. (Eds.). (2001). Fixed and fuzzy boundaries in higher education; A comparative study of (Binary) structures in nine countries. Den Haag: Adviesraad voor het Wetenschapsen.

KFH. (2005). Forschung und Entwicklung an Fachhochschulen. Grundsatzpapier: Bern.

Kyvik, S. (2006). Change Process in non-University Higher Education in Western Europe. In Paper for the CHER Annual Conference. University of Kassel.

Kyvik, S. (2004). Structural changes in higher education systems in Western Europe. Higher Education in Europe, 29, 393-409.

Kyvik, S., \& Skovdin, O.-J. (2003). Research in the non-university higher education sector-tensions and dilemmas. Higher Education, 45, 203-222.

Larédo, Ph. (2003). University research activities: On-going transformations and new challenges. Higher Education Management and Policy, 15(1), 105-123. 
Lepori, B. (2003). Understanding the dynamics of research policy: The case of Switzerland. Studies in Communication Sciences, 3(1), 77-112.

Lepori, B. (2006). Public research funding and research policy: A long-term analysis for the Swiss case. Science and Public Policy, 33(3), 205-216.

Lepori, B. (2007). Patterns, of diversity in the Swiss Higher Education System. In A. Bonaccorsi \& C. Daraio (Eds.), Universities as strategic units. Productivity and efficiency patterns in the European University system. Cheltenham: Edward Elgar.

Lepori, B., \& Attar, L. (2006). Research strategies and framework conditions for research in Swiss Universities of Applied Sciences. Report to the Federal Office of Professional Education and Technology.

Mayer, S., Sturn, D., \& Zellweger, E. (2006). Evaluierung des Kompetenzaufbaus für angewandte FuE an Fachhochschulen durch die KTI/CTI 1998-2004. Wien-Bern.

Meek, V. L., Goedegebuure, L., Kivinen, O., \& Rinne, R. (Eds.), (1996). The mockers and the mocked: Comparative perspectives on differentiation, convergence and diversity in higher education. Guilford, Pergamon.

OCDE. (1989). Politiques nationales de la science et de la technologie. Suisse: Paris.

OECD. (1998). Redefining tertiary education. Paris.

OECD. (2003a). Tertiary education in Switzerland. Paris.

OECD (2003b). Polytechnic education in Finland. Paris.

OECD. (2006). OECD reviews of innovation policies. Switzerland, Paris.

OFFT. (2002). Die Schweiz im weltweiten Innovationswettbewerb. Bern: Innovationsbericht.

Parry, G. (2003). Mass higher education and the English: Wherein the Colleges. Higher Education Quarterly, 57(4), 308-337.

Perellon, J.-F. (2001). The governance of higher education in a federal Country. The case of Switzerland. Tertiary Education and Management, 7(2), 211-224.

Perellon, J.-F. (2003). The creation of a vocational sector in Swiss higher education: Balancing trends of system differentiation and integration. European Journal of Education, 38(4), 341-355.

Pratt, J. (1997). The polytechnic experiment 1965-1992. Buckingam: The Society for Research into Higher Education and Open University Press.

Teichler, U. (2002). Diversification of higher education and the profile of the individual institution. Higher Education Management and Policy, 14(3), 177-188.

Teichler, U. (2003). The future of higher education and the future of higher education research. Tertiary Education and Management, 9, 171-185.

Trow, M. (1974). Problems in the transition from Elite to Mass Education. In: OECD (Ed.), Policies for higher education (pp. 51-101). Paris. 